the enlargement. In a condition such as tonsillar enlarge ment, a patient is justified in expecting a cure after operation.

In adults either complete or partial removal is a much more severe operation than in children, and the risk of haemorrhage is greater in both cases, though possibly greater when the tonsil is enucleated. As the operation is generally required owing to the tonsil being septic, the risk must be taken, unless the diathermic apparatus is available.

It is very doubtful if the haemorrhage after tonsillotomy is less than after tonsillectomy in children. The tonsillas: vessels are very small when they enter the organ. After enucleation they retract in healthy muscle tissue, and so casily close. In tonsillotomy they are slightly smaller when cut, but have not the firm tissue to help contraction, or may be held open by fibrous tissue. In enucleation the bleeding is sharp, but rapidly ceases; in partial removal there is more oozing after operation. Secondary haemorrhage may possibly occur oftener after complete removal, but this is very doubtful and it is extremely rare. In ovcr 1,000 cases in the past few years I have had no trouble with secondary haemorrhage. Improvement so rapidly and permanently follows complete removal that it is very doubtful if the $s \nabla$-.ity of the operation is greater or convalescence pro' 3 g 3 l.

If the tonsillar function we it importance, one would expect that the ill effects of complete removal would have already been shown, but improvement of health has been the universal rule, and, as mentioned above, a tonsil enlarged from chronic irritation is generally one of lowered resistance, and it is also doubtful whether it produces many lymphocytes.

If it were possible to say that a tonsil is healthy but enlarged owing to its endeavour to overcome a shortage of these cells and that it produced an appreciable number, then one would be justified in doing a partial operation.

The disadvantages of tonsillotomy are:

1. Subsequent operation or operations may be required owing to recurrence of enlargement, or to attacks of tonsillitis. I have removed tonsils from a boy who had had three previous operations.

2. The portion of the tonsil most liable to diseasenameiy, that coverea by the semilunar fold-is that most often left; in other cases deep septic or caseous foci arc left and brought nearer to infection.

3. Partial removal may be the starting point of tonsillitis, or the attacks may be more frequent after the operation.

4. Partial removal of a tuberculous tonsil may result in the dissemination of the disease.

5. When the pillars of the fauces are widely separated, partial removal does little or nothing to relieve the effects of this condition.

None of these objections apply to tonsillectomy, and only in public speakers and singers, where the roice may be altered by the operation, need one hesitate. In older people, or if hacmorrhage is feared, the tonsils can be removed by diathermy.

Considerable attention has been paid to the minimizing of haemorrhage. Crushing through the tissues with a b] unt-bladed guillotine appears to have the disadvantage that bruising will occur, and if so, infection of the raw surface will be more severe than if the blade had a dulled elge. Theoretically the risk of secondary haemorrhage ippear's to be increased.

Messrs. Whillis and Pybus's operation is a most satisfactory method, and the whole operation can be completed in less than a minute. If two sizes of guillotine (their vattern or Heath's) are used, according to the size of the tonsil, one rarely requires two incisions for any tonsil. The edge of the blade should be somewhat dulled, as by this means haemorrhage is lessened.

If after operation the gag is relaxed, firm but gentle pressure is applied to the raw surfaces with mops on handles and the face and head are bathed with cold water, the haemorrhage is considerably lessened.

BIBLIOGRAPHY.

Tallenger, Diseases of the Nose, Throat, and Ear. StClair Thomson, Jiseases of the Nose and Throat. Lockard. Tuberculosis of the Nose and Throat. J. M. Beattie and Yates, Journal of Pathology and Bacteriology, April, 1913. W. Stewart, BRITISH MredICAL JoסRYAL, May 31st, 1913. H. T. Ashley, ibid., May 31st, 1913. Whillis and Pybus ibid., November 25th, 1911 ; Lancet, July $17 \mathrm{th}, 1910$.

\section{EARACHE OF OBSCURE ORIGIN.}

BY

WILLIAM WILSON, M.D., B.Sc.,

HONORARY ASSISTANT SCRGEON, ST. JOHN'S IAR HOSPITAR, MANCHESTER.

PAIN in the ear and mastoid region may be due to irritation of any branch of the second and third division of the fifth, the seventh, ninth, or tenth nerves, of the cutaneous nerves of the neck, and the carotid sympathetic plexus. Certain toxaemias may also cause it.

I have described previously cases due to sphenoidal sinus disease and to stimulation of the posterior end of the inferior turbinal. ${ }^{2}$

The cases described below are interesting in that aural pain was the complaint for which the patients consulted me. In both cases the tympanum was apparently normal. The first gives an almost perfect mimicry of sphenoidal sinus empyema.

CASE I.-Meningeal Exudation.

A middle-aged woman, well nourished, and apparently healthy, complained of pain in the right ear of a few dars, luration. The pain was constant and suggested furunculosis of the external meatus. Examination and testing with tuning. forks gave negative results.

I did not consider the matter serious, but the patient returned in a few days, and then complainel of serere occipital pain, pain at the back of the eyes; the original pain in the ear was decreasing in severity. 'This snggested to me the possibility of acute suppuration in the ethmo-sphenoidal group of sinuses. This was rendered more probable by the nasal examination, which showed that the left nostril was rather narrow, but otherwise not abnormal. The septum was not markedly otherwise not a The right nostril was wide, the inferior turbinal was deflected. The right nostril was wide, the inferior turbinal was
somewhat atrophied, and there was crusting on the posterior somewhat atrophied, and there was crusting on the posterior lavage. The fronto-ethmoidal and antral sinuses on both sides were quite satisfactory on transillumination

I was surprised to find marked oedema of both optic dises, and a minute haemorrhage into the right disc. Examination of the nrine was entirely negative. By snipping away (under cocaine) a small portion of the middle turbinal, and next day catheterizing the sphenoidal sinus, I was able to prove that that sinus was not at fault. I therefore obtained the opinion of Dr. T. M. Bride, of the Eye Hospital, who was almost certain that the casc was one of specific papilloedema, She was immediately placed upon potassium iodide 20 grains thrice a day, with hrdrarg. cum creta 1 grain. In three dars vision had risen from $\frac{6}{3}$ to $\frac{6}{6}$ in the left eye; the right eye was not so fully recovered. The pains had entirely disappeared, and she "felt rine." Recovery was complete and rapid.

I can only conclude that this was a case of specific meningeal exudation limited to the sphenoidal region, thus simulating the reflex pains of a sphenoidal empyema. The pain in the $\epsilon a r$ and auricle resembling furunculosis was most probably reflected along the auriculo-temporal division of the inferior maxillaiy.

CASE Ir.-Chronic Osteo-periostitis.

A well-nourished woman came to me complaining of severe trmpano-mastoid pain on the left side. The opposite mastoid liad been operated upon some time previously. All medical methods of treatment had proved fut:le, and she demanded more radical treatment. The middle ear was apparently normal, but there was some doughy oedematous swelling ove and just above the mastoid. I opened the mastoid in the usua way, and found the periosteum thickened and hrperaemic. Fiaemorrhage was profuse. After considerable trouble a small antrum was found deeply situated. The bone was so hard that it broke a piece out of each of two new gonges. The electric burr was practically useless, so hard and ivory-like was the bone. The middle fossa and lateral sinus were exposed as a matter of routine, but nothing with the exception of this sclerosed bone was found sufficient to cause the symptoms. Owing to the trauma and consequent possibility of necrosis, the wound was not entirely closed. After healing the mastoid region became free from pain, but still there was slight oedema above the mastoid. She was ordered massage orer this area for half an hour twice daily, and in six weeks the oedelia had entirely subsided.

I considered the pathology of this ease to be a chronio osteo-periostitis, probably of "rheumatic" nature, and corresponding to the nodes met with in other parts of the bony skeleton.

REFERENCES.

1 Luigi Ümberto-Torrini, Rev. hebd. de laryng. d'otol. et de rhin., Mas, 1911. 2 Mredical Chronicle. Octobey, 1912. 